\title{
Thresholds of response to electric shock in previously undernourished rats
}

\author{
BY J. L. SMART, T. S. WHATSON AND J. DOBBING \\ Department of Child Health, University of Manchester, \\ Manchester $M_{13} 9 P T$
}

(Received 30 April 1975 - Accepted $17 \mathfrak{F u n e}$ 1975)

\begin{abstract}
I. Rats were undernourished in early life by feeding their mothers a restricted quantity of a good-quality diet during pregnancy and lactation. All offspring were fed ad lib. from weaning. Behavioural tests were done using adult males.

2. Thresholds of aversion to electric shock were determined in a rectangular box, one side of which was designated 'live' and the other 'safe' (o V side) for any particular shock level. Three $15 \mathrm{~min}$ sessions were given at each of five shock levels. Previously undernourished rats had a lower aversion threshold than controls. They spent more time than controls on the o V side at two intermediate levels of shock.

3. Other male rats were subjected to six graded series of brief, unavoidable shocks. Previously undernourished rats responded to a greater total number of shocks than controls.

4. These results support the hypothesis that previously undernourished rats have a lowered threshold of arousal.
\end{abstract}

Many of the differences in the behaviour of previously undernourished rats can be described loosely as over-reactions to the test situation. Rather more precisely, their response to a particular stimulus or set of stimuli is often greater than that of appropriate control animals (for review, Dobbing \& Smart, I973, x974). One hypothesis derived from such findings is that previously undernourished animals have a lowered threshold of arousal; that is, that they require less stimulation than normal to make them respond. The most direct prediction from this is that it ought to be possible to identify a level of stimulation to which previously undernourished rats will respond but to which controls will not respond.

A simple, though limited, way of testing the above hypothesis is to study thresholds of response to electric shock. Rats with a history of early nutritional deprivation have already been found to be more responsive in a Sidman avoidance test (Levitsky \& Barnes, 1970) and more inhibited by previous experience of high-intensity electric shock in passive avoidance situations (Levitsky \& Barnes, 1970; Smart, Dobbing, Adlard, Lynch \& Sands, r973). But no attempt has been made to titrate shock levels in order to assess thresholds of response. In the first experiment described in this paper the least shock which rats would seek to avoid (aversion threshold) was determined; and in the second experiment, thresholds were found for various overt responses to brief, inescapable shock.

\section{METHODS}

Rats. The rats were of the black-and-white hooded Lister strain. Conditions of rearing, mating routine and composition of diet have been described in detail elsewhere (Smart \& Dobbing, 1971; Smart et al. 1973). All mother rats had already borne 
and reared one litter. Control mothers had free access to a good-quality diet at all times; undernourished mothers were fed a restricted quantity of the same diet daily, which was about half that taken by control mothers. This amount $(\mathrm{g} / \mathrm{d})$ increased from Io throughout pregnancy to 15 during the first week of lactation, 20 in the second week of lactation, and 25 from day 15 to day 25 when the young were weaned. All rats were fed $a d l i b$. from weaning. Water was always freely available to all rats.

Litters were reduced to eight young on the day of birth, where possible to five males and three females. Only males were kept beyond weaning and these were housed two or three per cage in litter-mate groups until shortly before testing. Rats were weighed at birth, weaning, 6, 9, 12 and 15 weeks of age. The illumination of the animal rooms was on a $12 \mathrm{~h}$ white-light-I $2 \mathrm{~h}$ red-light cycle, switching from white light to red light at 12.00 hours. Both tests of behaviour were done during the red-light phase of the cycle, but animals were removed to a room in white light for the duration of the tests.

Expt I. Sixteen control (C) and thirteen previously undernourished (PU) male rats were used. These were drawn from seven $\mathrm{C}$ and six PU litters. They were caged singly for 5-10 $\mathrm{d}$ before testing, which was done at about $\mathrm{I}_{5}$ weeks of age.

Rats were tested in a rectangular aluminium box, $500 \times 220 \times 220 \mathrm{~mm}$ high: essentially a shuttle-box with the middle partition removed. The two 'halves' of the box could easily be discerned. The floor was a grid of $8 \mathrm{~mm}$ diameter stainless-steel bars, spaced $23 \mathrm{~mm}$ between centres. This was connected to a constant power shock source with scrambler, which could deliver electric shocks of variable voltage from a source resistance of $150000 \Omega$.

The testing procedure was based on that of Campbell (r967). Each rat was placed in the test box with the shock switched off and then, 2 min later, a shock of predetermined intensity was applied to the side on which the animal was located. When the animal crossed to the other side of the box, the shock switched off and remained off as long as the animal remained on that side. If the rat returned to the first side of the box, the shock was applied again and remained on as long as the animal remained there. After ${ }_{5}$ min the shock intensity was changed to another predetermined level, and the rat was tested again for preference for the 'no-shock' $(\mathrm{oV})$ side of the box. When shock levels were changed shock was always delivered to the side of the box occupied by the animal. The five shock levels (10, 20, 30,40 and $50 \mathrm{~V}$ ) were presented in a random order, and each level was presented three times. The order of presentation was the same for all rats: $20,10,30,50,40,30,10,50,40,20,50,30,10,20$ and $40 \mathrm{~V}$.

Expt 2. Seventeen $\mathrm{C}$ rats from seven source litters and fourteen PU rats from six litters were tested. All had been tested for spatial discrimination in a water maze, starting at about 14 weeks of age (Smart, unpublished results). At least $3 \mathrm{~d}$ elapsed between the end of the water-maze experiment and testing for responsiveness to shock at about 20 weeks. Four $\mathrm{C}$ and five PU rats had in addition been used in Expt $\mathrm{I}$, before water-maze testing. Their results were consistent with those for other members of their groups and were included with them.

Rats were tested in an aluminium box, $240 \times 210 \times 90 \mathrm{~mm}$ high, the front wall of which was transparent Perspex. The ceiling was sufficiently low to prevent the animals from rearing on their hind legs and thus minimizing or avoiding shocks. The 
Table $\mathrm{r}$. Body-weights $(g)$ of control $(C)$ and previously undernourished $(P U)$ male rats weaned at $25 d$ of age*

(Mean values and standard deviations; no. of rats in parentheses)

\begin{tabular}{|c|c|c|c|c|}
\hline Age (d) & $\mathrm{C}$ & PU & $\begin{array}{c}\text { Difference in } \\
\text { wt }(\%)\end{array}$ & $\begin{array}{c}\text { Statistical significance } \\
\text { of difference } \\
\text { between mean values } \uparrow: \\
P<\end{array}$ \\
\hline o (birth) & $\begin{array}{c}6 \cdot 1 \pm 0 \cdot 4 \\
(35)\end{array}$ & $\begin{array}{c}4 \cdot 6 \pm 0.6 \\
(31)\end{array}$ & 25 & 0.001 \\
\hline 25 & $\begin{array}{c}6 r \cdot 4 \pm 4 \cdot 6 \\
(35)\end{array}$ & $\begin{array}{c}20 \cdot 2 \pm 3 \cdot 6 \\
(25)\end{array}$ & 67 & 0.001 \\
\hline 105 & $\begin{array}{c}386 \cdot 7 \pm 3 I \cdot 5 \\
(35)\end{array}$ & $\begin{array}{c}277 \cdot 3 \pm 24 \cdot 3 \\
(24)\end{array}$ & 28 & 0.001 \\
\hline
\end{tabular}

floor was a grid of $4 \mathrm{~mm}$ diameter stainless-steel bars, spaced $14 \mathrm{~mm}$ between centres, through which electric shocks could be delivered from the source described previously.

The testing procedure was similar to that of Evans (196I). After 5 min habituation to the test box, six series of unavoidable electric shocks were delivered to the animal's feet. Each series consisted of ten stimulations at the following voltages: $5,10,20,30$, $40,60,80,100,140$ and $180 \mathrm{~V}$. The shocks were presented in an ascending or descending order on alternate series, with the first series an ascending one. Shocks were of I s duration and were presented at 30 s intervals. The interval between each series of shocks was 2 min. The shock source and test box were in separate rooms, such that shock presentation wąs not accompanied by any extraneous cues. A light cue, visible only to the observer, alerted him to shock onset.

Rats were scored at each shock presentation for the following behaviours: flinch, jump, vocalize. Flinch was any movement in response to shock onset which did not involve movement of the feet. Jump was the removal of one or more feet from the grid. Flinch and jump were therefore mutually exclusive, but vocalization could accompany either.

\section{RESULTS}

\section{Body-weight}

There were highly significant differences in body-weight between $\mathrm{C}$ and $\mathrm{PU}$ rats at all ages (Table r). At 15 weeks PU rats still had a weight deficit of $28 \%$.

\section{$\operatorname{Expt}$ 工}

After about the first $0.5 \mathrm{~h}$ in the box rats moved about little except for infrequent, short bouts of activity. When the shock levels were changed the rats usually remained where they were unless they found the shock unpleasant. Therefore, for the lower shock levels the proportion of time spent on the o V side was small (Fig. 1 ). The aversion threshold is defined here as the lowest voltage at and above which a rat spent more than $60 \%$ of its time on the $\circ \mathrm{V}$ side of the box: the value $60 \%$ was chosen to 


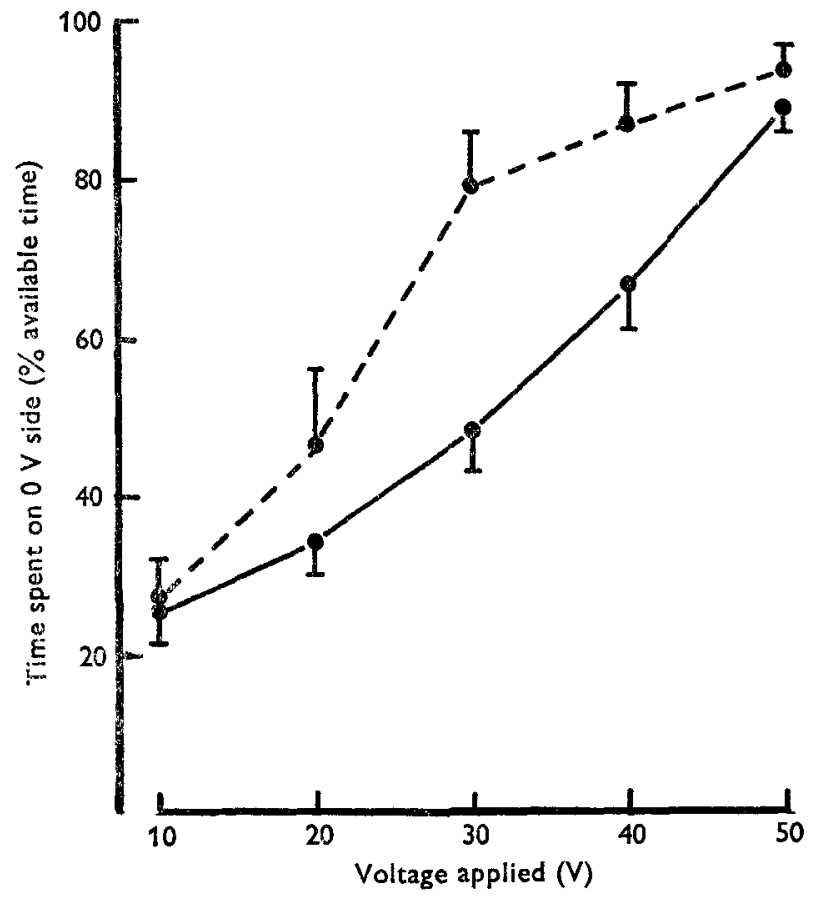

Fig. I. Expt r. Mean period of time (\% available time) spent on the 'no-shock' (o V) side of the test box by control (-) and previously undernourished (- $\left(-_{-}\right.$) rats at five levels of shock; for details of experimental procedure, see p. 5 I2. Results for the three sessions, at each voltage, were combined. The standard errors are represented by vertical bars.

reduce any random movement effect which might contaminate an aversion threshold defined at $50 \%$. One $\mathrm{C}$ and three PU rats could not be classified according to this scheme, in that they either had no threshold within the range of voltage used or appeared to have two thresholds. These results were omitted from further analyses. $\mathrm{PU}$ rats had a much lower aversion threshold, $29 \cdot 0 \pm 2 \cdot 8 \mathrm{~V}$ (mean and SE), than $\mathrm{C}$ rats, $4 \mathrm{I} \cdot 3 \pm \mathrm{x} \cdot 9 \mathrm{~V}(P<0.00 \mathrm{r}, t$ test $)$.

The periods of time ( $\%$ available time) spent on the $\circ \mathrm{V}$ side were subjected to an 'arc-sin' transformation before statistical analysis to render their frequency distributions more nearly Gaussian. PU rats spent more time on the $\circ \mathrm{V}$ side than $\mathrm{C}$ rats on the ' $30 \mathrm{~V}$ ' and ' $40 \mathrm{~V}$ ' tests $(P<0.005$ and $P<0.02$ respectively, $t$ tests $)$.

\section{Expt 2}

The animals were often continuously active during the first ascending series of shocks and it was extremely difficult to score accurately for flinch and jump responses. Results are therefore presented for the succeeding five series of shocks only. PU rats responded in some way to a greater total number of shocks than $\mathrm{C}$ rats (Table 2). None of the other measurements differed significantly between groups, although the differences were always in the direction of greater responsiveness by the PU animals. 
Table 2. Expt 2. Frequency of responses to shock*, and response thresholds $\uparrow(V)$ for control $(C)$ and previously undernourished $(P U)$ rats $\ddagger$

(Mean values with their standard errors)

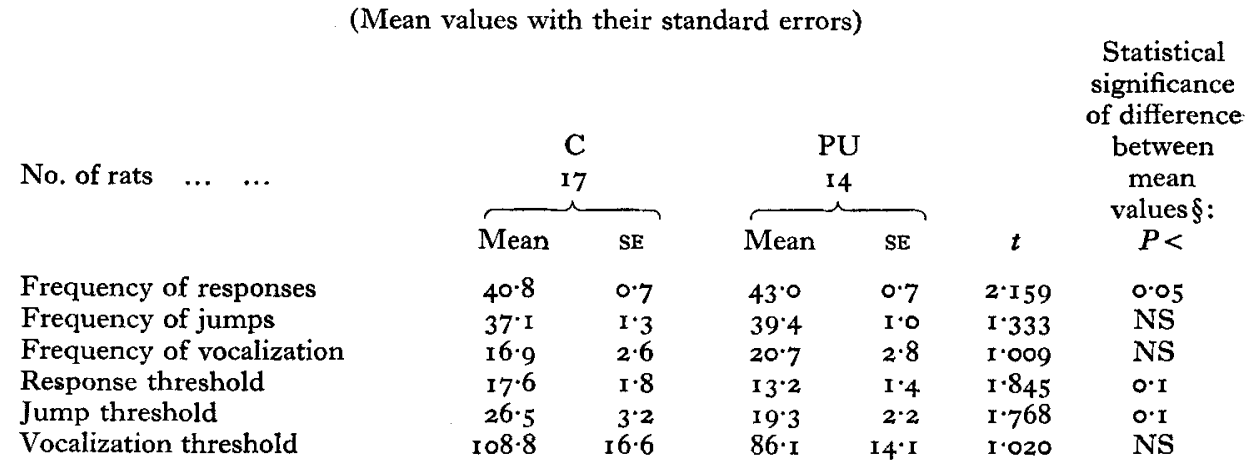

NS, not significant.

* Total no. of shock presentations, of a total of fifty, to which any response (or a particular response) was made; for definitions of responses, see p. 513 .

$\dagger$ The lowest voltage to which rats made any response (or a particular response) on at least three of the five series of shocks.

† For details of dietary treatment, see p. 5 I2.

$\S$ Student's $t$ test.

\section{DISCUSSION}

The above results lend support to the hypothesis that PU animals have a lower than normal threshold of arousal (Dobbing \& Smart, I974). In Expt I the PU rats' aversion threshold to electric shock was very highly significantly lower than that of the $\mathrm{C}$ rats, while in Expt 2 their thresholds of response to shock seemed again to be lower, although the differences in this instance were not significant. Furthermore, in Expt I there were significant differences in response to particular shock levels, and the patterns of change in time spent on the $\mathrm{V}$ side in the two groups were entirely consistent with a difference in threshold of arousal. $\mathrm{C}$ rats responded to $3^{\circ} \mathrm{V}$ as $\mathrm{PU}$ rats did to $20 \mathrm{~V}$, and to $40 \mathrm{~V}$ as $\mathrm{PU}$ rats would to $25 \mathrm{~V}$ (by interpolation, Fig. I).

Evidence of the greater reactivity of previously mal- or undernourished rats to high levels of electric shock (Levitsky \& Barnes, I970; Smart et al. 1973) has been discussed (see p. 5I I). Findings from the present aversion threshold tests indicate that this difference pertains at much lower shock intensities as well. Certain results from a recent paper by Cravens (1974) appear to lend further support to the present thesis, although they were not analysed or interpreted in this light. As a prelude to a test of hunger-drive, rats were tested for their preference for a 'safe' compartment over one in which they were given a brief electric shock. As the shock level was increased the performance of the $\mathrm{C}$ and $\mathrm{PU}$ rats diverged, with preference for the 'safe' side becoming more marked in the PU group. This divergence closely resembles that in Fig. 1 .

The differences in responsiveness to electric shock could be mediated in two ways: (I) there may be differences in input from the periphery to the central nervous system (CNS); (2) the input may be the same but the response of the CNS different. 
Input could be different for a variety of reasons. For instance, there may be differences in the structure, number or distribution of peripheral pain receptors. On the other hand these may be the same for both groups, but their response may be different for other reasons. Heightened autonomic activity might cause an increase in skin conductivity mediated directly, for example, by sweat glands, or indirectly, as by a greater tendency to wet the shock grid with urine. This presupposes some difference between groups in initial response of the autonomic nervous system to the situation, though it is easy to see how a 'vicious circle' might develop.

One possible differential response of the CNS has already been mentioned involving autonomic activity. However, there may be differences at a higher level centrally. In tentative support for this, it would appear from the present experiments that differences in responsiveness to shock are most clear in situations in which the shock is avoidable. Presumably avoidance is a function of higher CNS activity.

The adrenal gland may also be relevant in the present context, in that both adrenalin and glucocorticoids have been reported to influence the aversion threshold (Paré \& Cullen, I97I). Apparently both types of hormone act to reduce the threshold; that is, they render rats more sensitive to shock. There is already some preliminary evidence of a lasting effect of early undernutrition on the hypothalamic-pituitary-adrenocortical axis (Adlard \& Smart, 1972), which may relate in some complex way to the effect on responsiveness to shock reported here.

The authors thank the Medical Research Council for supporting this research and the National Fund for Research into Crippling Diseases for additional financial assistance.

\section{REFERENCES}

Adlard, B. P. F. \& Smart, J. L. (1972). F. Endocr. 54, 99.

Campbell, B. A. (1967). In Early Behavior, p. 43 [H. W. Stevenson, E. H. Hess and H. L. Rheingold, editors]. New York: John Wiley \& Sons Inc.

Cravens, R. W. (1974). Devl Psychobiol. 7, 6r.

Dobbing, J. \& Smart, J. L. (I973). In Ethology and Development, Clinics in Developmental Medicine, no. 47, p. 6 [S. A. Barnett, editor]. London: Spastics Society and Heinemann.

Dobbing, J. \& Smart, J. L. (1974). Br. med. Bull. 30, i64.

Evans, W. O. (1 961). Psychopharmacologia 2, 318 .

Levitsky, D. A. \& Barnes, R. H. (1970). Nature, Lond. 225, 468.

Paré, W. P. \& Cullen, J. W. (I97I). Horm. Behav. 2, 139.

Smart, J. L. \& Dobbing, J. (1971). Brain Res. 28, 85.

Smart, J. L., Dobbing, J., Adlard, B. P. F., Lynch, A. \& Sands, J. (1973). F. Nutr. ro3, I327. 